ТРУБЧАНІНОВА К. А., к.т.н., доцент, КРОЩЕНКО Д. О., магістрант

(Український державний університет залізничного транспорту)

\title{
Метод попереднього планування безпроводової локальної мережі стандарту IEEE 802.11
}

Досліджуються різні підходи планування при проектуванні безпроводової мережі стандарту IEEE 802.11 у приміщеннях. У статті подано формули та розрахунки методом завдання фіксованої кількості користувачів на точку $i$ результати імітаційного проектування мережі Wi-Fi, побудованого на програмі D-Link Wi-Fi Planner Pro.

Ключові слова: Wi-Fi, IEEE 802.11, безпроводова мережа, планування безпроводової локальної мережі.

\begin{abstract}
Вступ
При проектуванні безпроводової мережі в приміщеннях застосовують різні підходи, які майже завжди містять кілька етапів $[1,5]$ :

1. Оцінка кількості точок доступу залежно від передбачуваної кількості користувачів Wi-Fi i послуг, які мають бути їм надані.

2. Розміщення точок доступу на плані-схемі приміщення 3 урахуванням його розмірів, матеріалів, 3 яких виготовлені стіни і меблі, а також розміщення користувачів.

Одним 3 найпростіших способів визначення кількості точок доступу $€$ завдання фіксованої кількості користувачів на точку.

Наприклад, існує рекомендація використовувати одну точку доступу на 20 користувачів при відсутності шифрування i одну точку на 15 користувачів при використанні будь-якого шифрування. Такий підхід дуже простий, але має низку недоліків. По-перше, така кількість точок доступу може виявитися надмірною, що призведе до зайвих витрат як на безпроводовий вузол, так i на організацію його розміщення (електроживлення, підключення до проводової локальної мережі). По-друге, при великій кількості точок доступу, розміщених в одному приміщенні, розрахованому на більше число користувачів (наприклад, конференц-зал або лекторій), вони можуть заважати один одному i ї потрібно розносити по різних каналах, що може бути складним при використанні діапазону 2,4 ГГц (наприклад, якщо використовується технологія 802.11g).
\end{abstract}

(ㄱ.К. А. Трубчанінова, Д. О. Крощенко, 2020
Другий спосіб виходить з вимог за рівнем сигналу. Наприклад, вважається, що для доступу в Інтернет (електронна пошта та веб-серфінг) досить забезпечити на всій території приміщення рівень сигналу не гірше ніж - (68-70) дБм. Такий підхід, як правило, вимагає застосування спеціалізованого програмного забезпечення для попереднього розрахунку або використання вимірювань на місці, коли передбачувана до використання точка доступу розміщується в різних місцях приміщення i проводиться вимір іiі сигналу на можливих точках розміщення користувачів. Як правило, цей спосіб пропонує занижене число точок доступу, завдяки чому на практиці побудована мережа може не впоратися 3 навантаженням. До того ж повне покриття приміщення може виявитися не потрібним у тому випадку, коли користувачі компактно розміщуються в одній частині приміщення, а друга частина приміщення не використовується.

Третій спосіб попереднього визначення кількості точок доступу виходить 3 вимог щодо швидкості доступу залежно від необхідних користувачам послуг.

У результаті таких розрахунків може вийти деяка середня кількість точок доступу. Однак питання нерівномірності розміщення користувачів також необхідно враховувати на етапі розміщення точок доступу на плані-схемі приміщення $[4,5]$.

Метою роботи $\epsilon$ дослідження способів попереднього планування безпроводової локальної мережі, яке передбачає не тільки визначення кількості точок доступу, але і енергетичний розрахунок, щоб розміщені в приміщенні точки доступу не впливали одна на одну, а їх сигнал не виходив за межі приміщення i не впливав на безпроводові мережі, розташовані зовні приміщення. 


\section{Основна частина}

Для прикладу, оцінимо аналітичним методом кількість точок доступу, необхідну для організації безпроводової мережі в лекторії. 3 огляду на те що на сьогодні переважна більшість мобільних пристроїв використовують технологію $802.11 \mathrm{n}$, будемо орієнтуватися на неї. $Є$ аудиторія на 130 студентів, які, наприклад, будуть брати участь в онлайн-опитуваннях, використовувати веб-браузер, читати пошту, читати i викладати інформацію в соціальні мережі.

Тепер ми можемо спланувати мережу. Нехай кожен iз 130 студентів має із собою ноутбук або планшет і використовує його для доступу в Інтернет.

Початкові дані:

1. Пристрої:

- планшети (802.11n, 20 МГц, 1 потік), 65 Мбіт /с, реальна швидкість (ТСР) 30 Мбіт / с;

- ноутбуки (802.11n, 20 МГц, 2 потоку), 144 Мбіт/с, реальна швидкість (ТСР) 70 Мбіт / с.

2. Додатки: web, e-mail, соціальні мережі, 3 необхідною гарантованою швидкістю для одного користувача 1 Мбіт / с.

3. Кількість пристроїв: 65 ноутбуків, 65 планшетів, використовуються одночасно. При цьому:

$D_{T}=0.5$ - частка планшетних комп'ютерів i смартфонів (Tablet PC);

$D_{L}=0.5$ - частка ноутбуків (Laptop);

$D_{2.4 G H z}=0.6$ - частка пристроїв, що працюють у діапазоні 2,4 ГГц;

$D_{5 \mathrm{GHz}}=0.4$ - частка пристроїв, що працюють у діапазоні 5 ГГц.

Планшетні комп'ютери використовують 20 МГц канал в один потік, що забезпечує теоретичну швидкість роботи 72 Мбіт/с. Реальна швидкість при цьому буде приблизно у два рази меншою $\mathrm{i}$ дорівнюватиме $F_{T}=35 \mathrm{M \sigma im} / \mathrm{c}$.

Ноутбуки використовують 20 МГц - канал у два потоки, що забезпечує теоретичну швидкість роботи 144 Мбіт/с. Реальна швидкість при цьому буде приблизно у два рази меншою $\mathrm{i}$ дорівнюватиме $F_{L}=70 \mathrm{M \sigma im} / \mathrm{c}$.

Тепер визначимо коефіцієнт ефірного часу (Airtime) для кожного з типів пристроїв:

$$
\begin{aligned}
& A_{T}=\frac{F}{F_{T}}=0.029 . \\
& A_{L}=\frac{F}{F_{L}}=0.014 .
\end{aligned}
$$

Загальний коефіцієнт ефірного часу для всіх пристроїв кожного типу буде дорівнювати

$$
\begin{aligned}
& A_{T}^{\text {all }}=A_{T} \cdot N \cdot D_{T}=1.857 . \\
& A_{L}^{\text {all }}=A_{L} \cdot N \cdot D_{L}=0.929 .
\end{aligned}
$$

Загальний коефіцієнт ефірного часу з урахуванням службового трафіку буде дорівнювати:

$A=\left(A_{T}^{\text {all }}+A_{L}^{\text {all }}\right) \cdot 1.25=3.482$.

Далі необхідно визначити кількість радіомодулів, що працюють у діапазоні 2,4 ГГц, і радіомодулів, що працюють у діапазоні 5 ГГц.

$$
\begin{aligned}
& N_{2.4 G H z}=A \cdot D_{2.4 G H z}=3 . \\
& N_{5 G H z}=A \cdot D_{5 G H z}=2 .
\end{aligned}
$$

Таким чином, аналітичний метод планування безпроводової локальної мережі стандарту IEEE 802.11 показав, що для організації безпроводової мережі потрібно або 3 точки доступу, що працюють у діапазоні 2,4 ГГц, і 2 точки доступу, що працюють у діапазоні 5 ГГц, або 3 дводіапазонні точки доступу 2, 4 / 5 ГГц 3 можливістю одночасної роботи в обох діапазонах.

Необхідно враховувати, що ця оцінка, хоч і має гарну точність, усе ж є попередньою, і отже, при розміщенні точок доступу на плані-схемі приміщення, а також при проведенні енергетичного розрахунку i складанні частотного плану вона може бути скорегована [1, 4].

Далі, для підтвердження або спростування, проведемо імітаційне моделювання планування безпроводової локальної мережі Wi-Fi. В рамках цієї статті використовується програма D-Link Wi-Fi Planner Pro [2], яка призначена для первинного аналізу плану приміщення 3 метою розміщення на ньому точок доступу Wi-Fi. Програма орієнтована на використання обладнання D-Link. Програма дає змогу враховувати різні параметри приміщення, зокрема не тільки фактичну площу приміщення, але i тип, матеріал та кількість перегородок. Крім того, програма дозволяє вести розрахунки як при автоматичному розміщенні точок доступу, так і при ручному. Розмістити точки треба вручну так, щоб по всій робочій зоні забезпечити рівень сигналу не гірше ніж -65 дБм.

Як було вже сказано, при розміщенні точок доступу дуже важливо визначити, 3 яких матеріалів зроблені стіни, перекриття, конструкційні елементи та меблі у приміщенні, i вже 3 урахуванням цього 
проводити розміщення обладнання і вибір антен, які будуть використовуватися разом з точками доступу.

Наприклад, однією $з$ найпоширеніших помилок при розміщенні точок доступу є встановлення точки зі всеспрямованою антеною біля металевої або залізобетонної стіни або конструкції. В цьому випадку металева поверхня буде відображати сигнал. Діаграма направленості антени зміниться, ставши спрямованою. До того ж виникне потужне багатопроменеве поширення (multipath), оскільки половина випромінюваної потужності буде йти до металевої стіни/поверхні i, відбиваючись назад, створить інтерференцію своєму ж корисному випромінюванню. Іншим прикладом може бути розміщення точки біля ємностей і труб з водою, яка інтенсивно поглинає високочастотне випромінювання (особливо в частотному спектрі 2,4 ГГц).

Основним методом вирішення $є$ винесення точок доступу з внутрішніми антенами (або самих зовнішніх антен) за межі перешкод, забезпечуючи безперешкодне випромінювання 3 урахуванням діаграми спрямованості антен.

Вплив матеріалу стін і перегородок, встановлених у приміщенні, можна оцінити за табл. 1 [3].

Таблиця 1

Втрата ефективності сигналу 802.11 при
проходженні через різні середовища

\begin{tabular}{|l|c|c|}
\hline \multicolumn{1}{|c|}{ Перешкода } & $\begin{array}{c}\text { Додаткові } \\
\text { втрати, дБ }\end{array}$ & $\begin{array}{c}\text { Ефективна } \\
\text { відстань, \% }\end{array}$ \\
\hline Відкритий простір & 0 & 100 \\
\hline $\begin{array}{l}\text { Вікно без } \\
\text { тонування } \\
\text { (металізованого } \\
\text { покриття) }\end{array}$ & 3 & 70 \\
\hline $\begin{array}{l}\text { Вікно з } \\
\text { тонуванням } \\
\text { (металізованим } \\
\text { покриттям) }\end{array}$ & $5-8$ & 50 \\
\hline Міжкімнатна стіна & $15-20$ & 15 \\
\hline Несуча стіна & $20-25$ & $10-15$ \\
\hline $\begin{array}{l}\text { Бетонна } \\
\text { підлога/стеля }\end{array}$ & $15-25$ & 10 \\
\hline $\begin{array}{l}\text { Монолітне } \\
\text { залізобетонне } \\
\text { перекриття }\end{array}$ & $20-25$ & \\
\hline
\end{tabular}

Ефективна відстань становить величину, до якої зменшиться радіус дії після проходження відповідної перешкоди порівняно 3 відкритим простором. Наприклад, якщо на відкритому просторі радіус дії Wi-Fi досягає 100 м, то після проходження першої міжкімнатної стіни він зменшиться до $15 \%$ від цієї величини, тобто до 15 м, а після другої - до $15 \%$ від цього значення (до 2,2 м).

Також необхідно враховувати, що рівень сигналу зменшується пропорційно квадрату відстані, тому швидкість спадає природним шляхом у міру віддалення від точки доступу.

На основі початкових даних і 3 урахуванням вищесказаного маємо результат розрахунку програми D-Link Wi-Fi Planner Pro для лекторію ( рис. 1).

Оцінювана зона покриття сигналу 802.11 позначена на рис. 1 червоним (рівень сигналу -25 дБм) та помаранчевим кольором (рівень сигналу -35 дБм). Зеленим та блакитним позначені осередки, які, можливо, будуть не повністю перекриті сигналом Wi-Fi (рівень сигналу - -55...-75 дБм).

Знаючи зону покриття, складається попередній план розміщення точок доступу на всій території приміщення. При цьому слід ураховувати, що осередки, частково перекриті сигналом, варто перекривати двома точками доступу.

Бачимо, що результати розрахунку відрізняються від початкових 7 точок доступу (правило «20 абонентів на точку»), а також від 3 точок за результатами енергетичного розрахунку. 
І Н Ф О Р М А І Й Н О - К Е Р У Ю Ч І С И С Т МИ Н А 3 А Л І 3 Н И ЧН О М У Т Р А Н П О Р Т І

D-Link Wi-Fi Planner PRO

s szrpatz@gmail.com (logi

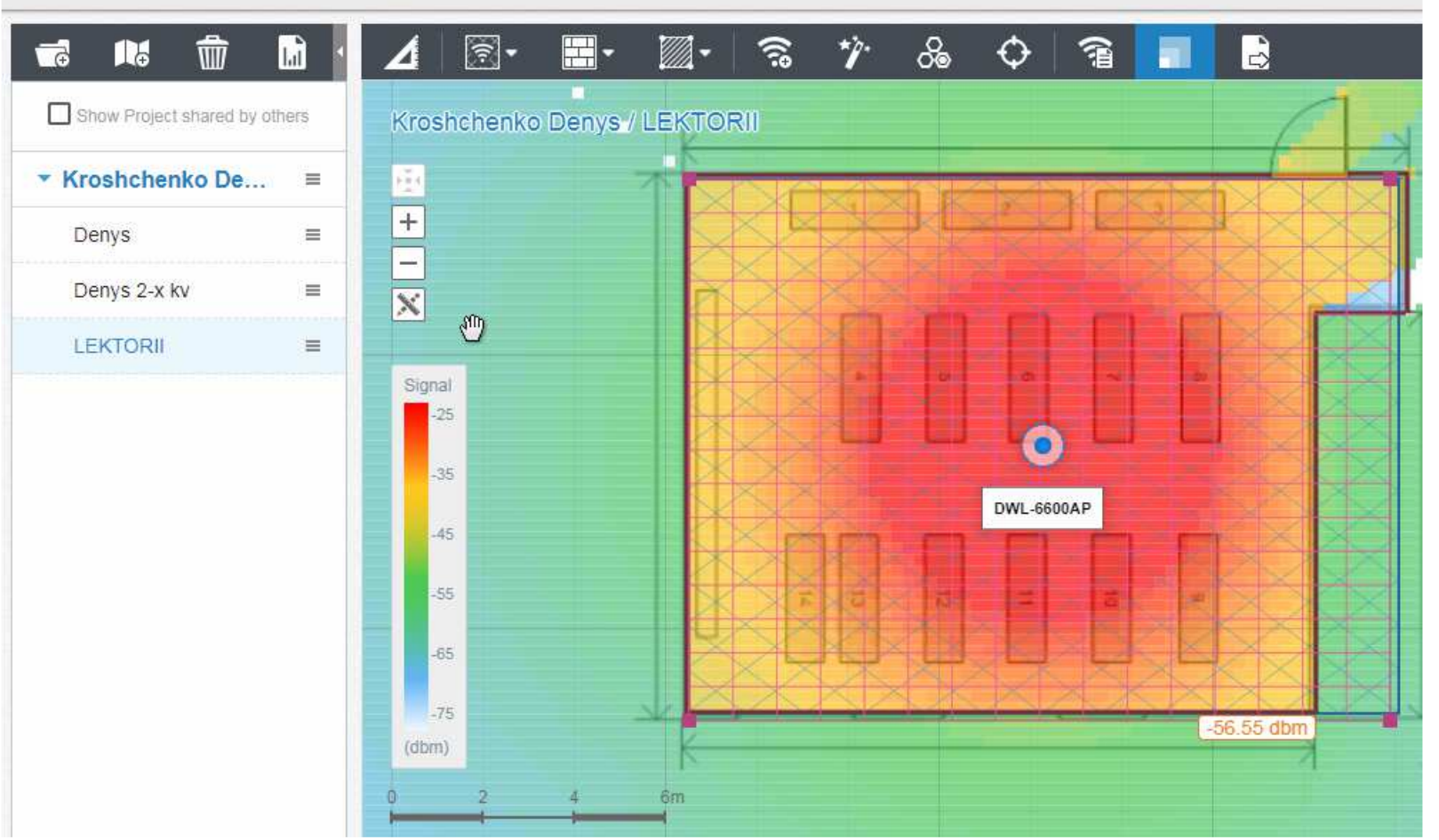

a)

D-Link Wi-Fi Planner PRO

szrpatz@gmail.com (logout)

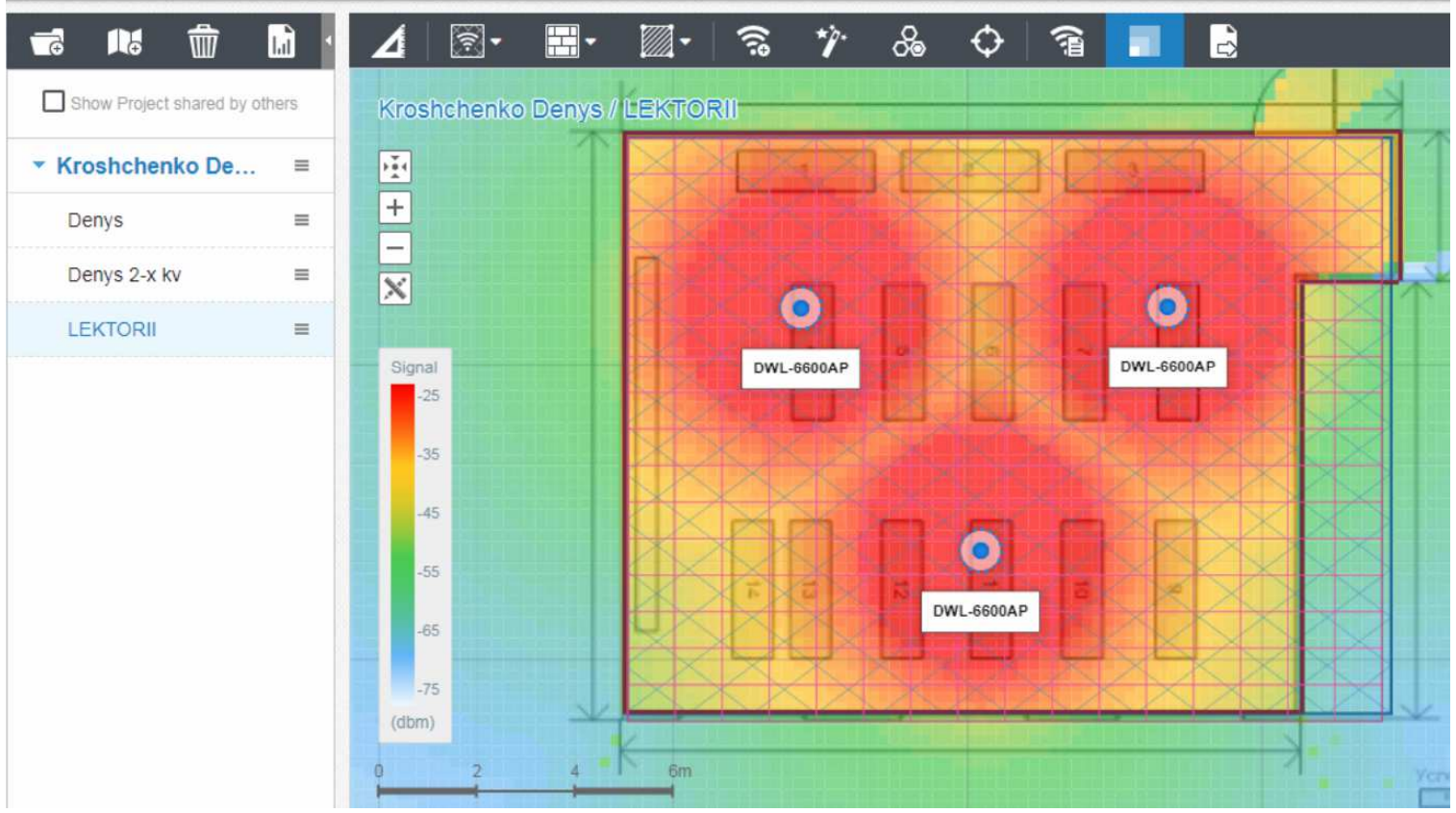

б)

Рис. 1. Результати імітаційного планування безпроводової локальної мережі Wi-Fi: a - для діапазону 2.4 ГГц; б - для діапазону 5 ГГц 


\section{Висновки}

У сьогоднішньому світі Wi-Fi найчастіше використовують два підходи до планування мережі. Або заздалегідь задають число абонентів на одну точку доступу, а потім розраховують загальну кількість необхідного обладнання. Або відразу розставляють точки доступу по приміщеннях за допомогою спеціалізованого ПЗ, так щоб рівень сигналу був не нижче заданого порога (наприклад, -65 дБм).

Розглянуті в роботі обидва підходи показали, до чого призводить таке планування. Наприклад, у нас $\epsilon$ аудиторія в університеті, розрахована на 130 студентів. Виходячи 3 логіки «20 абонентів на точку» та враховуючи одночасний доступ усіх студентів до мережі Інтернет під час занять, нам потрібно встановити 7 точок доступу. Але чому саме 20 абонентів на точку, чому не 50, не 80 чи не 15 ? Крім того, точки доступу бувають різними. Деякі мають один радіомодуль, що працює в діапазоні 2,4 ГГц, деякі - 2 або навіть 3 радіомодулі, які можна налаштувати для одночасної роботи відразу в декількох діапазонах. Потім, план аудиторії був внесений у програму-планувальник і розставлені точки доступу таким чином, щоб забезпечити вимоги до мережі. Програма D-Link Wi-Fi Planner Pro показала, що в аудиторію потрібно встановити 1 (в діапазоні 2,4 ГГц ) точку доступу та 3 (в діапазоні 5 ГГц ), щоб забезпечити покриття 3 рівнем сигналу не гірше 65 дБм (для надання студентам тільки доступ в Інтернет).

Як видно, результати аналітичного і імітаційного планування тільки частково збігаються, тому при плануванні мереж Wi-Fi потрібно спланувати розміщення точок доступу за допомогою спеціалізованого ПЗ, не забувши знизити потужність кожної з точок доступу до рівня потужності Wi-Fiчіпа, вбудованого в планшет студента.

\section{Список використаних джерел}

1. Сайко В. Г., Казіміренко В. Я., Літвінов Ю. М. Мережі бездротового широкосмугового доступу: навч. посіб. Київ: ДУТ, 2015. 196 с.

2. Wi-Fi Planner PRO http://www.dlink.ru/tools/wi-fi/\#tour.

3. Коэффициенты затухания сигнала Wi-Fi при прохождении через различные среды. URL: https://goo.gl/UqdzYp.

4. Структура стандартів IEEE 802.x. URL: http://matveev.kiev.ua/archnet/glava3/002.htm.

5. Serkov O., Panchenko N., Trubchaninova K., Kurtsev M. Ultra Wideband Communication Technology in the Transport and Logistics Systems. ICTE in Transportation and Logistics 2019. ICTE ToL 2019. Lecture Notes in Intelligent Transportation and Infrastructure. Springer, Cham. 2020. P. 262-270.
Трубчанинова К. А., Предварительное Аланирование К локальной сети стандарта IEEE 802.11.

Аннотация. Исследуются различные подходы планирования при проектировании беспроводной сети стандарта IEEE 802.11 в помещениях. В статье приведены формулы и расчеты методом задачи фиксированного количества пользователей на точку и результаты имитационного проектирования сети $\mathrm{Wi}$ $\mathrm{Fi}$, основанного на программе D-Link Wi-Fi Planner Pro.

Ключевые слова: Wi-Fi, IEEE 802.11, беспроводная сеть, планирование беспроводной локальной сети.

Trubchaninova K. A., Kroshchenko D. O. Advance Planning for IEEE 802.11 Wireless LAN.

Abstract. Examines various approaches of planning in the design of wireless network standard IEEE 802.11 in the premises. The article gives formulas and the calculation method of tasks a fixed number of users on point, and the results of simulation designing Wi-Fi network based on the program D-Link Wi-Fi Planner Pro. The program is designed for the initial analysis of the floor plan with the aim of placing it on the access points Wi-Fi. She focused on the use of the equipment D-Link, to allow for the different room settings, in particular, not only the actual floor space, but the type, material and number of partitions. In addition, D-Link Wi-Fi Planner Pro allows you to conduct calculations similar to automatic access point placement or manual. When the AP placement is very important to determine what materials are made of walls, floors, structural elements and furniture in the room, and had given this to hold equipment placement and selection of antennas to be used with access points.

Keep in mind that the effective distance has a value, which will decrease the radius of action after the passage of the relevant obstacles compared to open space, and the fact that the signal decreases proportional to the square of the distance, so speed comes naturally as the distance from the access point. D-Link Wi-Fi Planner Pro showed that the audience need to install $1(2.4 \mathrm{GHz})$ access point and 3 (in the $5 \mathrm{GHz}$ band) to provide a coating with a signal level not worse than $-65 \mathrm{dBm}$ (for providing students with only Internet access).

As can be seen, results of analytical and simulation planning only partially coincide, so when planning $\mathrm{Wi}-\mathrm{Fi}$ networks need to plan the placement of access points with specialized software, not forgetting to reduce the power of each of the access points to the power level of the WiFi chip built into the tablet student.

Keywords: Wi-Fi, IEEE 802.11, wireless network, wireless LAN planning.

Надійшла 30.04 .2020 p. 
Трубчанінова Карина Артурівна, кандидат технічних наук, дочент, дочент кафедри транспортного зв'язку Украӥнського державного університету залізничного транспорту, м. Харків, Украӥна. E-mail: tka2@ukr.net, ORCID: http://orcid.org/0000-0003-2078-2647.

Крощенко Денис Олексійович, магістрант кафедри транспортного зв'язку Украӥнського державного університету залізничного транспорту, м. Харків, Україна. E-mail: deniskroshchenko96@gmail.com

Trubchaninova Karyna, PhD. Sc., associate professor, Department of transport communication of Ukrainian State University of Railway Transport. E-mail: tka2@ukr.net, ORCID: http://orcid.org/0000-0003-2078$\underline{2647 .}$

Kroshchenko Denys, gs of Department of transport communication of Ukrainian State University of Railway Transport.E-mail: deniskroshchenko96@gmail.com 